\title{
Detailed study on the comfort properties of Zari fabric
}

\begin{abstract}
Indian silk industry is one of the premier industries producing silk and next to china. Today the sericulture industry is faced with many problems and silk from china is being imported to combat shortage of silk. One among the product using silk is zari yarn. The Zari yarn is a value added yarn manufactured using silk. This yarn is three components consisting of $40 \%$ of silver, $0.5 \%$ of gold and $59.5 \%$ of silk in the core position. This yarn is manufactured using the wrap spinning technique in which the flattened silver wire is wrapped on to the silk yarn and then coated with gold. The zari yarn is mostly used in saree border. The saree woven using the zari yarn will weigh around $800-1000$ gms depending on the design structure. The silk saree with Zari thread work will cost around 30000-84000/- depending on the weight of zari yarn used in the silk fabric. Lot of research work has been carried out to improve the texture of silk yarn. More work has been carried out in the past to improve the aesthetic and comfort properties of silk fabric. Even though the zari yarn has been used in the silk fabric manufacturing, so far there has been no research work conducted to study the zari yarn properties and its characteristics. The effect of plasma treatment on the zari yarn also studied in terms of weight loss and improvement in adhesion properties which will help in improved performance of zari yarn. The zari yarn made up of Bombyx mori silk as core is is used to produce the fabric. The comfort properties of zari yarn are also studied by using the Kawabata Evaluation system. The low stress mechanical properties of zari fabric with and without plasma treatment have been studied.
\end{abstract}

Keywords: zari yarn, plasma treatment, comfort properties, core yarn
Volume I Issue I - 2017

\author{
Sundaresan S,' Thangamani K, ${ }^{2}$ Arunraj $A^{\prime}$ \\ 'Department of Textile Technology, Kumaraguru College of \\ Technology, India \\ ${ }^{2}$ Department of Textile Technology, Kumaraguru College of \\ Technology, India
}

Correspondence: Sundaresan S, Assistant professor (SRG), Department of Textile Technology, Kumaraguru College of Technology, Coimbatore-64I 049 ,Tamil Nadu, India, Tel No 94 4348 1084, Email shobsundar@gmail.com

Received: January 24, 2017| Published: February 20, 2017

\section{Introduction}

The textile sector in today's scenario is moving towards value addition products and new innovation. Lot of developments has been taking place in Machinery, Technology and New product development. The textile field is expanding its using through Technical Textiles, Medicals Textiles, Nano technology etc.

The textile product made from silk is of more lustrous and gives rich look to the wearer. The cost of the silk product is also very high when compared to other textile products. The silk manufacturing is a specialized skill required area and the Zari silk production needs a very good technical skill and knowledge. In this regard one of the most valued products is made by using silk yarn. The silk yarn can be converted to metallic yarn which is commercially known as zari yarn. This type of highly precious yarn is mostly used for making sarees which is of most valuable cost. Even though the zari yarn has been used in the silk fabric manufacturing, so far there has been no research work conducted to study the zari yarn properties and its characteristics. The effect of plasma treatment on the zari yarn also studied in terms of weight loss and improvement in adhesion properties which will help in improved performance of zari yarn. The zari yarn made up of Bombyx mori silk as core is used to produce the fabric. The comfort properties of zari yarn are also studied by using the Kawabata Evaluation system. The low stress mechanical properties of zari fabric with and without plasma treatment have been studied.

\section{Literature review}

Plasma is defined as a state where a significant number of atoms and/or molecules are either electrically, thermally or magnetically charged or ionized. Plasma in general refers to the excited gaseous state consisting of atoms, molecules, ions, Meta stables, and excited state of these as well as electrons, such that the concentration of positively and negatively charged species is roughly the same. Theoretically, plasma is referred to as a "fourth state of matter" and is characterized in terms of the average electron temperature and the charge density within the system. A slight yellowing with no visible changes to the hydrophobicity of the fabric was found by ${ }^{1}$ when polyester fabric was treated with argon plasma. When treated with oxygen, the fabric showed slight discoloration, and the surface became more wettable. A study on the effect of plasma treatment on different textile materials by $^{2}$ revealed that surface properties of textiles can be readily altered without impairment of their bulk mechanical properties by treating with gas plasma. Modification and functionalization of textile materials through plasma treatments have a great potential in future. The mechanical and surface properties and handle of wool and cotton fabrics after different stages of treatment using the KES-FB system by were studied by. ${ }^{3}$ The investigation revealed that remarkable changes in mechanical properties of wool and cotton took place after oxygen plasma treatment. The surface properties and surface roughness were changed by plasma treatment as per the experimental results. This leads to an increase in low-stress mechanical properties such as bending and shear rigidities. Significant increases in bending and shearing characteristic values for plasma treated fabrics dyed below the boil $\left(85^{\circ} \mathrm{C}\right)$ were found in a research by. ${ }^{4}$ Plasma treated fabrics were stiffer and crisper than the untreated fabrics as highlighted by the subjective hand tests. ${ }^{5}$ Carried out Investigation on the effect of 
nitrogen plasma on the morphology and properties of Tassar silk fibers and fabrics using the techniques of transmission electron microscopy, scanning electron microscopy, x-ray diffraction, and infrared spectroscopy, which showed that the plasma treatment is effective only on the surface of the fibers and fabrics. Due to the treatment, wettability increased and the drying rate became faster, but the creaserecovery angle decreased. The fundamental understanding and the commercial application of plasma technology in the textile industry were discussed by ${ }^{6}$ who studied specific properties of textile products that influence plasma-textile interactions. He clarifies the need for a generic approach to the plasma treatment of textiles. All treatments were done in a parallel plate, $13.56 \mathrm{MHz}$ capacitive coupled reactor designed for the study of textile behavior in plasma, with oxygen as working gas. Comparison of Morphological changes in the surfaces of untreated and plasma treated wool fabrics using scanning electron microscopy were studied by Karahan et al. ${ }^{7}$ The physical properties of wool fabrics such as thermal properties, water vapor permeability, air permeability and friction properties were affected by atmospheric plasma treatments. It was noticed that there was a considerable increase in thermal resistance, water vapor permeability and friction properties and the pilling tendency, bursting strength, thermal conductivity and air permeability values decreased. It was revealed in an investigation Hesse $\mathrm{A}^{8}$ that three process parameters like time power and type of gas used in the plasma reactor will influence the efficiency of the plasma process. The species that participate in plasma reactions can interact either physically or chemically with the substrate to modify the surface. Low pressure plasma treatment on wool fibre properties modifies the cuticle surface of the fibre as per the investigation by. ${ }^{9}$ These results in enhanced generation of new hydrophilic group's thereby improving wettability dye ability fibre cohesion and shrink resistance. The number of cross linkages on the fibre surface was considerably reduced due to the plasma treatment which helps in improving the printability and shrink-resistance of the wool fabrics. Atmospheric plasma treatment on wool results in increased the surface friction coefficients which effects the fiber-fiber interaction and thus reduces the pilling tendency according to a study by Kan $\mathrm{CW} .{ }^{10}$ The atmospheric plasma treatment has an etching effect on the fiber surface and increases the fabric surface roughness and space, resulting in increased amount of air kept between the yarns and fibers. In a study on the effect of plasma pre-treatment, along with titanium dioxide coating on cotton fabrics, found that the treatment improves the wrinkle recovery property of cotton fabric. ${ }^{11}$ It was seen that titanium dioxide treatment had a negative effect on tensile properties, compression properties and surface friction and variation, while shearing and bending properties were improved by the treatment, via plasma treatment improves all sensory properties except surface friction and variation. Silk surface modification due to plasma treatment and its effect on dyeing was studied. ${ }^{12}$ The treatment of silk surfaces using oxygen and Air plasma mainly affected the conformation change from the amide-II random coil to the amide-I $\beta$-sheet structure. The silk surfaces were notably roughened by the oxygen and Argon plasma treatments and the surface roughness was increased with increasing plasma treatment time. The adsorption of lac dye on the untreated silks and treated silks was found to follow the pseudo-first-order kinetic model. The amount of dye adsorbed at equilibrium, the adsorption capacity for the pre-treated silks was much improved when compared with that of the untreated sample. Applied the technology of objective fabric measurement was applied to pure silk fabrics of different qualities of woven fabrics such as satin, twill etc. ${ }^{13}$ and the weight of the fabric ranging from 21 to $82 \mathrm{~g} / \mathrm{m}^{2}$. The instrumentally measured properties of the finished silk fabrics are discussed in terms of fabric weight, thickness, tensile properties shear, bending, compression, surface friction and surface geometry. The mean values of these low stress mechanical and surface properties for finished pure silk fabrics are reported. Studied the his tensile, bending, shearing, compression and surface properties of mulberry and Tassar silk fabrics have been studied to investigate their hand values. ${ }^{14}$ Using the data obtained, the quality characteristics of mulberry and Tassar silk fabric have been objectively evaluated and then compared. It is observed that mulberry silk fabric is better in terms of shear. stiffness, bending rigidity, geometrical roughness, hand values and draping behavior, but possesses lower compression resilience as compared to Tassar silk fabric. Made some modifications to the simple conventional method for determining low- stress mechanical properties of fabrics to make it applicable for finished silk fabrics. ${ }^{15}$ the bending rigidity of the fabrics has been obtained from the tensile stress strain curves and the shear rigidity by bias extension. The results obtained by the new method shows a good correlation to the results obtained by Kawabata evaluation test method and is found good for a series of finished silk fabrics.

\section{Material and method}

The silk yarn of 16, 18 deniers (parallel yarn) is used as core material for producing zari yarn. And Bombyx Mori silks were used as core yarn. For the wrapper element 16-micron silver wire is used. For coating the silver wrapped silk yarn 24 carat gold solution is used. The zari yarn components are shown in Figure 1.

\section{Results and discussion}

The zari yarn is produced by using wrap spinning technique and is coated with gold using the dip dry technique. Bombyx Mori silk is used as core yarn. The zari yarn is coated with gold content of $0.25 \%$. Two types of zari yarn is produced such as

\section{i. Core yarn with plasma treatment}

ii. Core yarn without plasma treatment.

Fabric is produced using handloom. The fabric is tested for low stress mechanical properties and the total handle value (THV) also found. For plasma treatment oxygen gas is used.

The details of plasma reactor are given in Table 1 and the reactor is shown in Figure 2. The raw silk and degummed silk yarn was assessed for their tensile strength. The degummed silk is treated using the plasma reactor with oxygen gas as a plasma medium. It is done to improve the surface roughness of the silk yarn so that during the wrapping process, the silver wire gets wrapped firmly with core material. The Table 2 gives the details of tenacity of Bombyx mori silk yarn.

After degumming the strength Bombyx mori silk yarn reduced from $32.7 \mathrm{gf} / \mathrm{tex}-26.5 \mathrm{gf} / \mathrm{tex}$. The reason for the strength reduction after degumming is $(16 \%)$ due the removal of sericin content during the degumming process. Further the process of plasma treatment reduces the strength of Bombyx mori silk yarn to $8.1 \%$.The reason for the strength reduction after plasma treatment is due to the surface etching created on the surface of the fibre. The degummed Bombyx mori silk yarn is converted to suitable Zari yarn using silver wrapping with the wrap spinning machine. The spindle speed in wrap spinning machine is kept as $920 \mathrm{rpm}$ throughout the study. The sample produced is gold 
coated with $0.25 \%$ gold solution. The Zari yarn produced is given plasma treatment and the tensile strength details are given in the Table 3 .

Table I Plasma reactor particulars

\begin{tabular}{lll}
\hline S. No & Particulars & Details \\
\hline I & Type of Machine & Plasma systems \\
2 & Model & HPVT-PS \\
3 & Gas used & Oxygen \\
4 & Distance between plates & $3 \mathrm{~cm}$ \\
5 & Plasma voltage & 400 Volts \\
6 & Plasma Treatment Time & 5 Minutes \\
\hline
\end{tabular}

Table 2 Tensile strength of Bombyx mori silk

\begin{tabular}{ll}
\hline Details & $\begin{array}{l}\text { Average tensile strength } \\
\text { (gf/tex) }\end{array}$ \\
\hline Raw Bombyx mori silk & 32.7 \\
$\begin{array}{l}\text { Degummed Bombyx mori silk } \\
\text { Plasma treated Bombyx mori silk }\end{array}$ & 26.5 \\
( 5 minutes duration) & 24.3 \\
\hline
\end{tabular}

Table 3 Tenacity of Zari yarn

\begin{tabular}{|c|c|c|c|}
\hline \multirow{2}{*}{$\begin{array}{l}\text { Sample } \\
\text { code }\end{array}$} & \multirow[t]{2}{*}{ Details } & \multicolumn{2}{|c|}{ Tensile strength gf/tex } \\
\hline & & $\begin{array}{l}\text { Before } \\
\text { plasma } \\
\text { treatment }\end{array}$ & $\begin{array}{l}\text { After } \\
\text { plasma } \\
\text { treatment } \\
(0.25 \% \\
\text { gold } \\
\text { coating) }\end{array}$ \\
\hline i & $\begin{array}{l}\text { Degummed Bombyx mori } \\
\text { silk+ Silver wrapping+ } \\
\text { Gold coating }(0.25 \%)\end{array}$ & 19.32 & - \\
\hline ii & $\begin{array}{l}\text { Degummed Bombyx mori s } \\
\text { plasma treatment ( } 5 \text { minut } \\
\text { Silver wrapping+ Gold coat }\end{array}$ & $\begin{array}{l}\text { with } \\
\text { duration)+ }\end{array}$ & 17.8 \\
\hline
\end{tabular}

\section{Sem images of zari yarn}

To know the surface modification zari yarn due to the plasma treatment SEM images are taken. From the SEM images Figure 3 of zari yarn and it components, we can clearly see that the surface roughness is created on the yarn after plasma treatment. This enables the yarn to become more frictional resistance which will improve the weavability of yarn. Also the gold coating on the yarn will be fixed on the surface of the yarn which will not get peeled off during the usage, so the life of the zari thread get increased.

The comfort properties of fabric woven by using zari yarn made from Tassar silk core and Bombyx mori silk core are tested using the Kawabata Evaluation system (KES). This experiment is done to determine the total handle value (THV) of the fabric and to find any improvement in the comfort properties and handle value of the Zari yarn woven fabric. Investigation also made to find the significance of plasma treatment effect given to the zari yarn on the comfort properties of the fabric. The samples produced using the zari yarn is woven by using the hand loom with identical parameters. The ends/inch and picks /inch of the fabric is kept as 120 and plain weave has been used to construct the fabric. The GSM of the fabric has been maintained as 60 for all the samples. The details of the fabric produced are given in the Table 4.

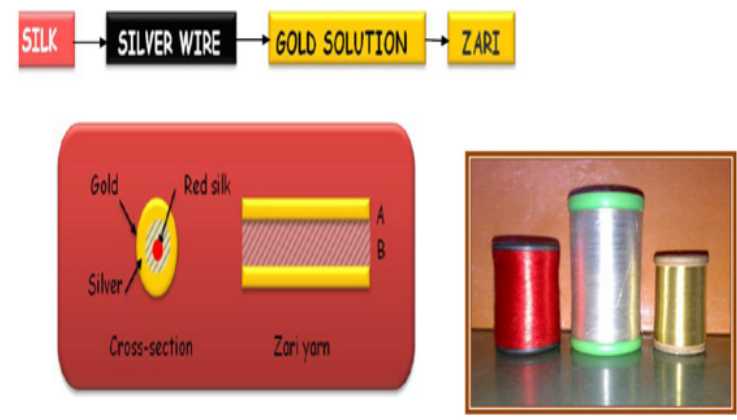

Figure I Zari yarn components.

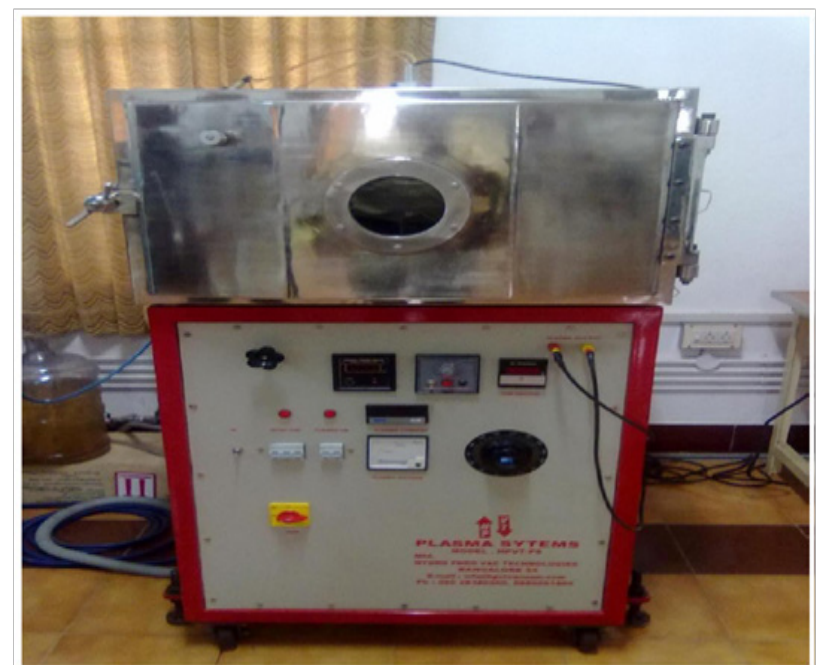

Figure 2 Plasma reactor.

Table 4 Cloth particulars

\begin{tabular}{ll}
\hline Warp and weft yarn & Zari yarn \\
EPI(Ends per inch), PPI(Picks per inch) & I20inches \\
Structure & Plain \\
GSM & $60 \mathrm{gm} / \mathrm{sq} \cdot \mathrm{m}$
\end{tabular}

From the Table 5 it can be concluded that there is a significant difference between the low stress mechanical properties of zari yarn woven (using Bombyx Mori silk as core yarn) fabric with and without plasma treatment. From the results obtained from KES system the low stress mechanical properties of the fabric woven with $0.25 \%$ gold coated yarn which treated for 5 minutes in plasma reactor sample (ii) has much improved tensile, bending, shear, surface and compression properties compared to sample (i).

From the Figure 4, the low stress mechanical properties of zari yarn woven fabric (Bombyx Mori Core) with $0.25 \%$ gold coatingplasma treatment for 5 minutes, shows a better KES values that that of 
the untreated fabric. The tensile properties show a $15 \%$ improvement and the surface properties shows a $4.9 \%$ improvement because of plasma treatment. The KES chart is given in the (Figure 5) (Figure 6) which indicates much improvement in low stress mechanical property after plasma treatment.

The behavioral property of the zari yarn woven fabric has been expressed in terms of total handle value. From the Table 6 the total handle value (THV) of the zari yarn woven fabric (Bombyx mori core) is increased due to plasma treatment. There is a significant improvement in the total handle value and it has been noted that there is an $8 \%$ increase in the total handle value of the zari fabric (Bombyx mori core) after plasma treatment. The total handle value also represented in the (Figure 7) (Figure 8) shows a much improved handle value after plasma treatment.

The tailoring process control based on fabric tensile and shear property is shown in the (Figures 9) (Figure 10) which indicates much improvement in the behavior of fabric for tailoring process after plasma treatment.

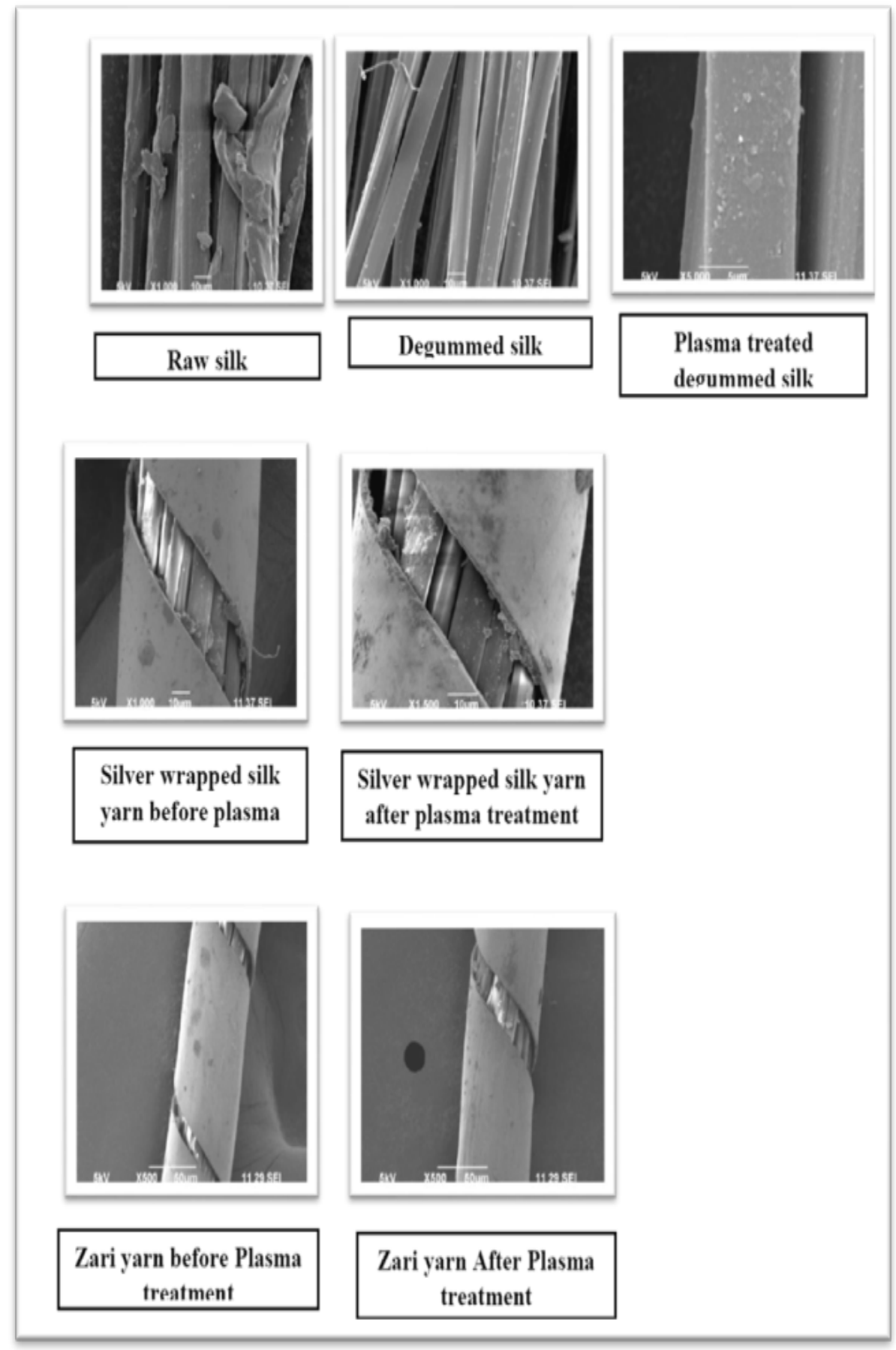

Figure 3 SEM images of zari yarn. 

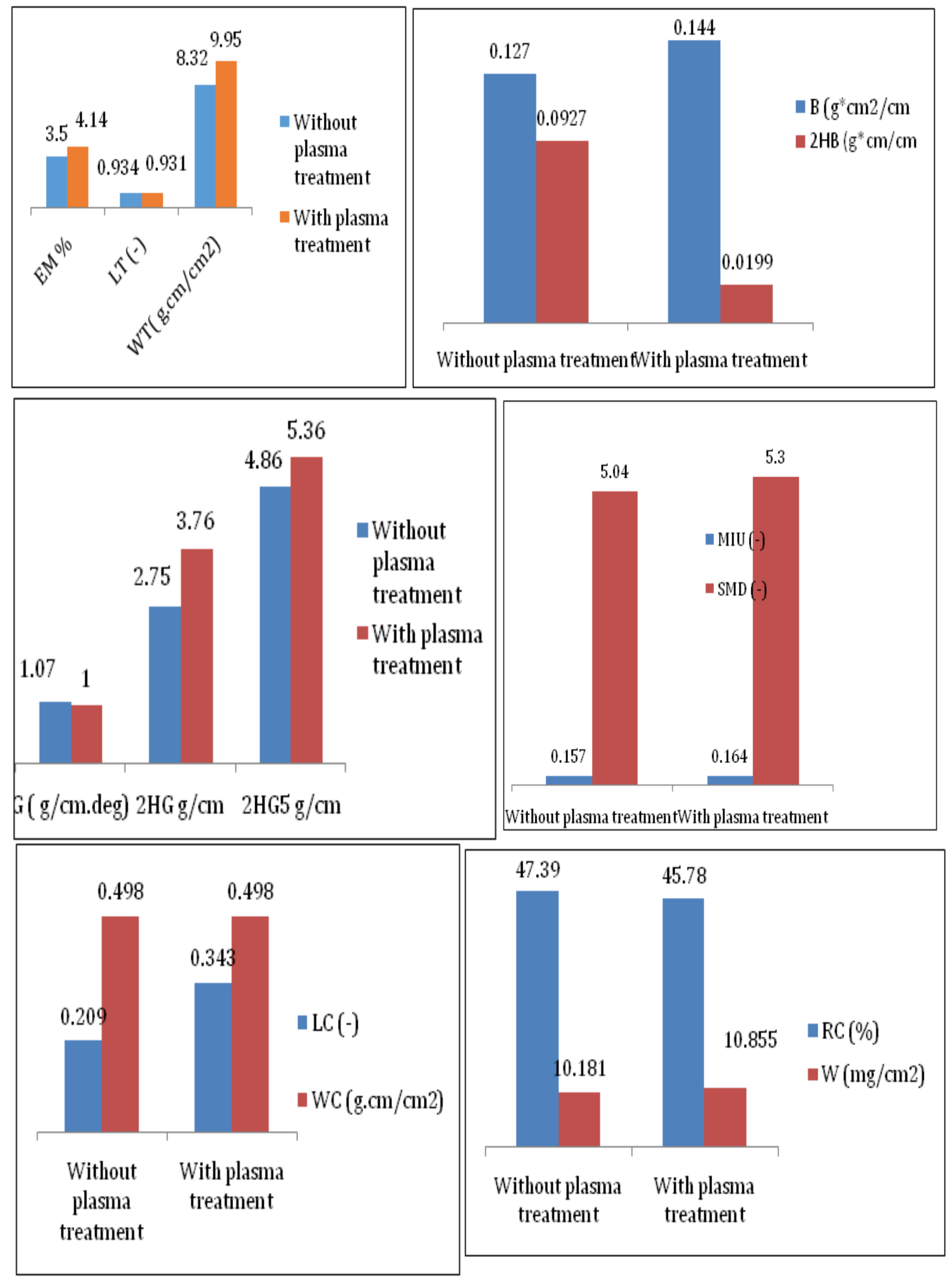

Figure 4 Graph showing the KES values of Zari cloth (Bombyx Mori core). 


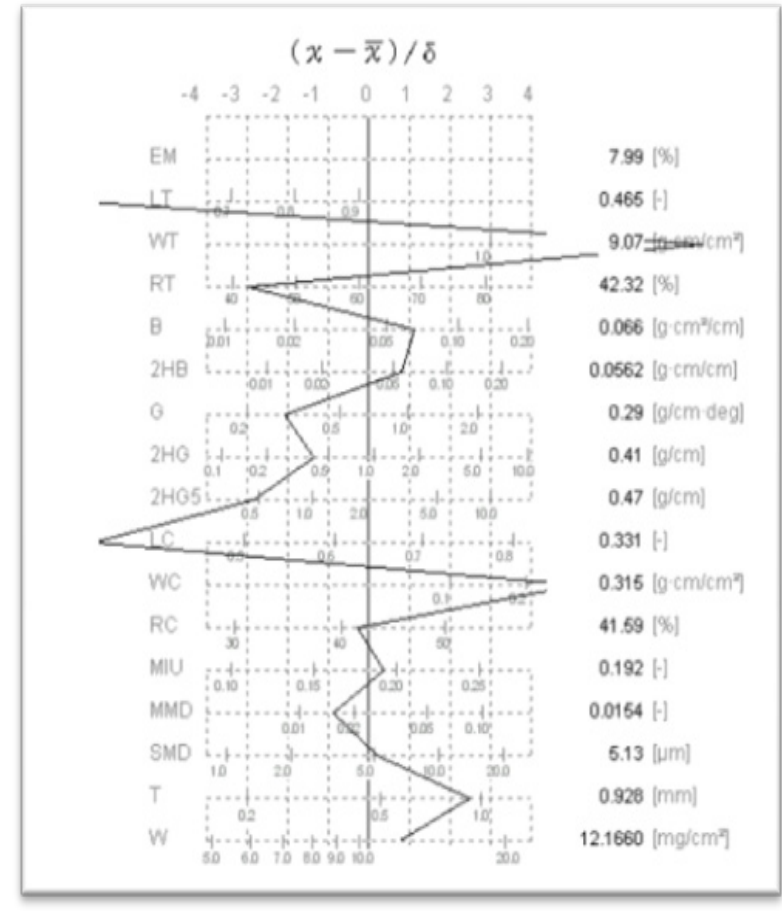

Figure 5 KES Chart before plasma treatment.

Table 5 KES values of Zari yarn woven fabric (Bombyx mori core)

\begin{tabular}{|c|c|c|c|}
\hline \multirow{4}{*}{ Property } & \multirow{4}{*}{ Symbol } & \multicolumn{2}{|c|}{$\begin{array}{l}\text { Zari fabric produced with } \\
\text { bombyx mori silk as core yarn }\end{array}$} \\
\hline & & $\begin{array}{l}\text { Without } \\
\text { plasma } \\
\text { treatment }\end{array}$ & $\begin{array}{l}\text { With plasma } \\
\text { treatment(5 } \\
\text { Minutes } \\
\text { duration) }\end{array}$ \\
\hline & & \multicolumn{2}{|c|}{0.25 gold coating } \\
\hline & & Sample i & Sample ii \\
\hline \multirow{4}{*}{ Tensile } & EM \% & 3.5 & 4.14 \\
\hline & LT (-) & 0.934 & 0.931 \\
\hline & WT( g.cm/cm²) & 8.32 & 9.95 \\
\hline & RT\% & 59.05 & 58.4 \\
\hline \multirow{2}{*}{ Bending } & B $\left(g^{*} \mathrm{~cm}^{2} / \mathrm{cm}\right.$ & 0.127 & -0.144 \\
\hline & $2 \mathrm{HB}\left(\mathrm{g}^{*} \mathrm{~cm} / \mathrm{cm}\right.$ & 0.0927 & -0.0199 \\
\hline \multirow{3}{*}{ Shear } & G (g/cm.deg) & 1.07 & I \\
\hline & $2 \mathrm{HG} \mathrm{g} / \mathrm{cm}$ & 2.75 & 3.76 \\
\hline & $2 \mathrm{HG} 5 \mathrm{~g} / \mathrm{cm}$ & 4.86 & 5.36 \\
\hline \multirow{3}{*}{ Surface } & MIU (-) & 0.157 & 0.164 \\
\hline & NMD (-) & 0.0458 & 0.0369 \\
\hline & SMD (-) & 5.04 & 5.3 \\
\hline \multirow{3}{*}{ Compression } & LC (-) & 0.209 & 0.343 \\
\hline & $W C\left(\mathrm{~g} . \mathrm{cm} / \mathrm{cm}^{2}\right)$ & 0.498 & 0.498 \\
\hline & RC (\%) & 47.39 & 45.78 \\
\hline \multirow{2}{*}{ T\&W } & $\mathrm{T}(\mathrm{mm})$ & 1.416 & 1.079 \\
\hline & $W\left(\mathrm{mg} / \mathrm{cm}^{2}\right)$ & 10.181 & 10.855 \\
\hline
\end{tabular}

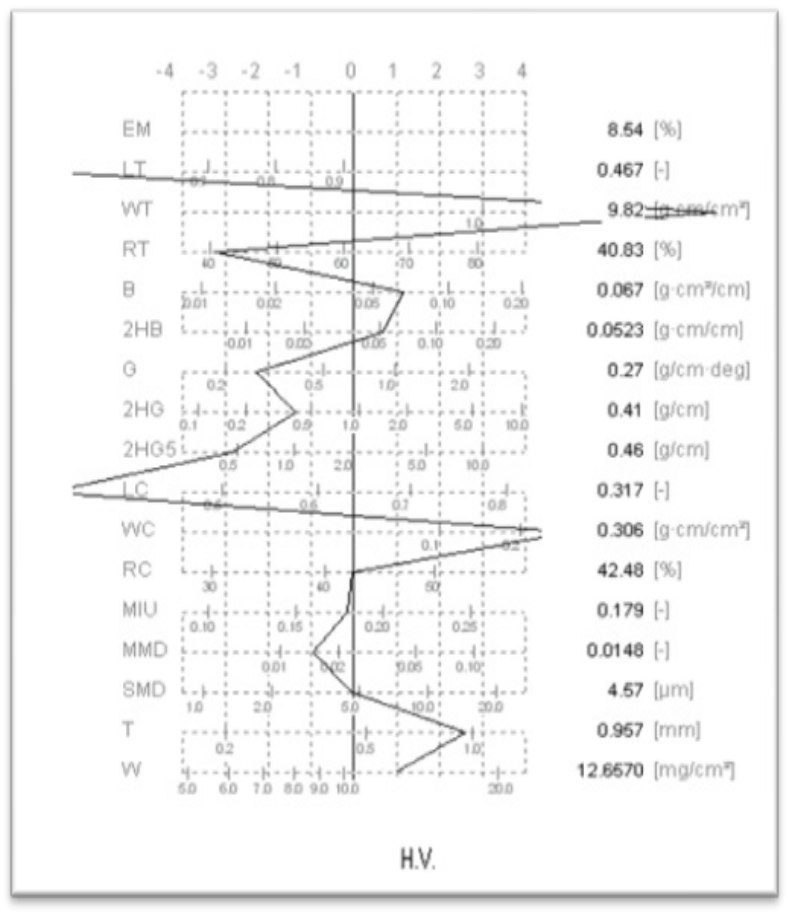

Figure 6 KES chart after Plasma treatment.

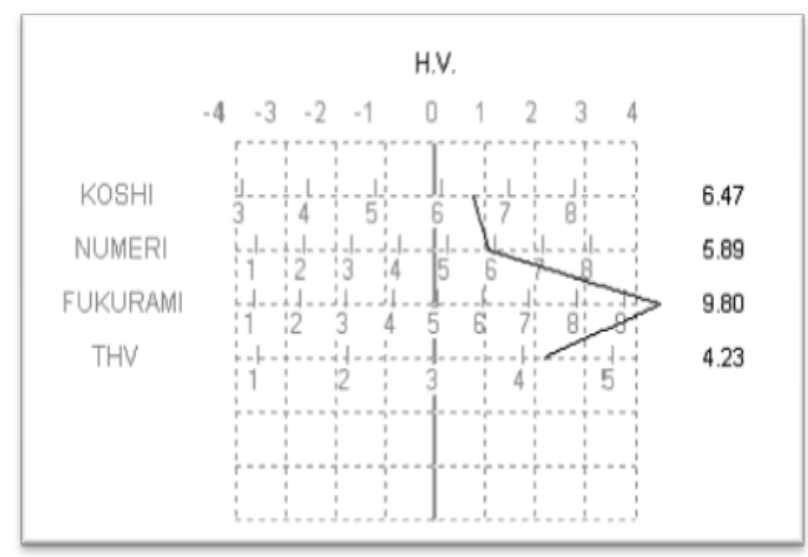

Figure $7 \mathrm{THV}$ before Plasma Treatment.

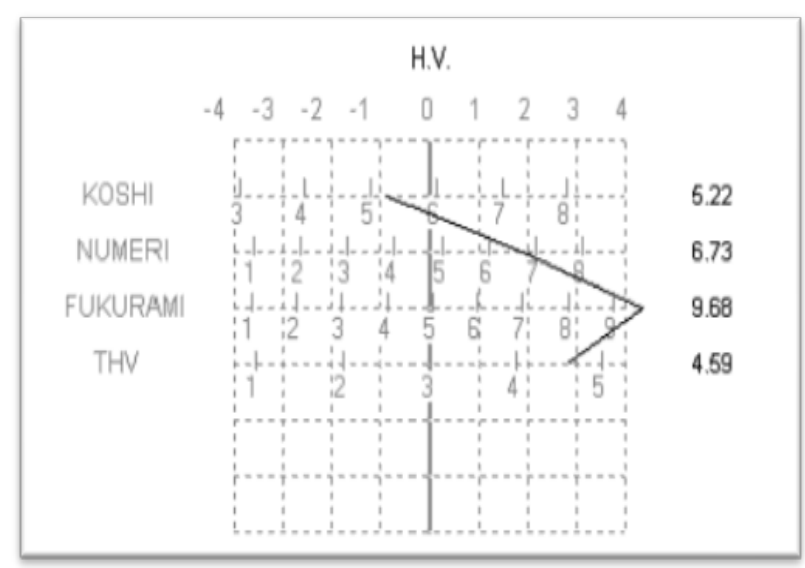

Figure $8 \mathrm{THV}$ after plasma treatment. 
Table 6 Total handle value of zari fabric

\begin{tabular}{lll}
\hline \multirow{2}{*}{ Details } & \multicolumn{2}{l}{$\begin{array}{l}\text { Zari fabric produced with } \\
\text { bombyx mori silk yarn as } \\
\text { core yarn }\end{array}$} \\
\cline { 2 - 3 } & $\begin{array}{l}\text { Without } \\
\text { plasma } \\
\text { treatment }\end{array}$ & $\begin{array}{l}\text { With } \\
\text { plasma } \\
\text { treatment } \\
\text { (5Minutes } \\
\text { duration) }\end{array}$ \\
\cline { 2 - 3 } & $\mathbf{0 . 2 5 \%}$ gold coating \\
\hline KOSHI(Stiffness) & 6.47 & 5.22 \\
NUMERI (crimpiness) & 5.89 & 6.73 \\
FUKURAMI (Fullness \& & 9.8 & 9.68 \\
softness) & 4.23 & 4.59 \\
Total Handle Value(THV) & &
\end{tabular}

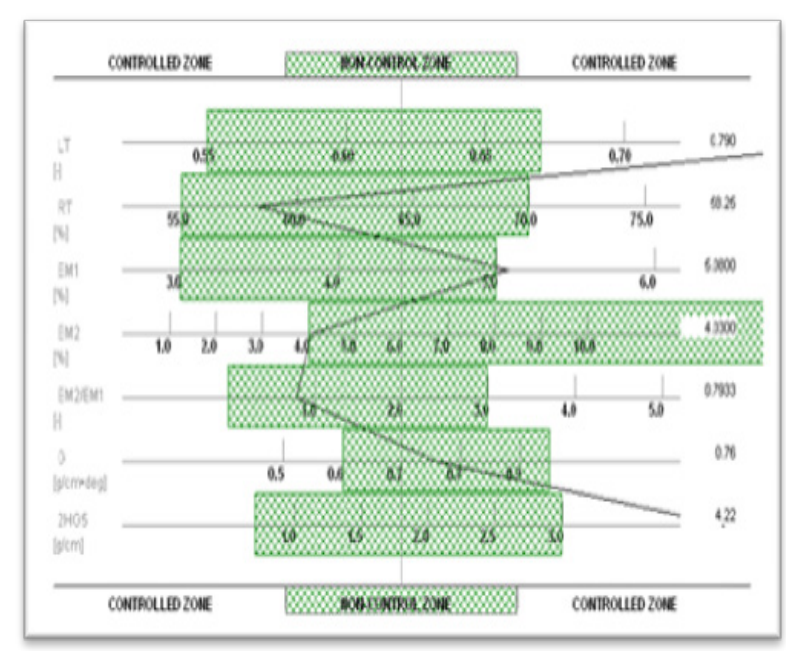

Figure 9 Tailor ability chart before plasma treatment.

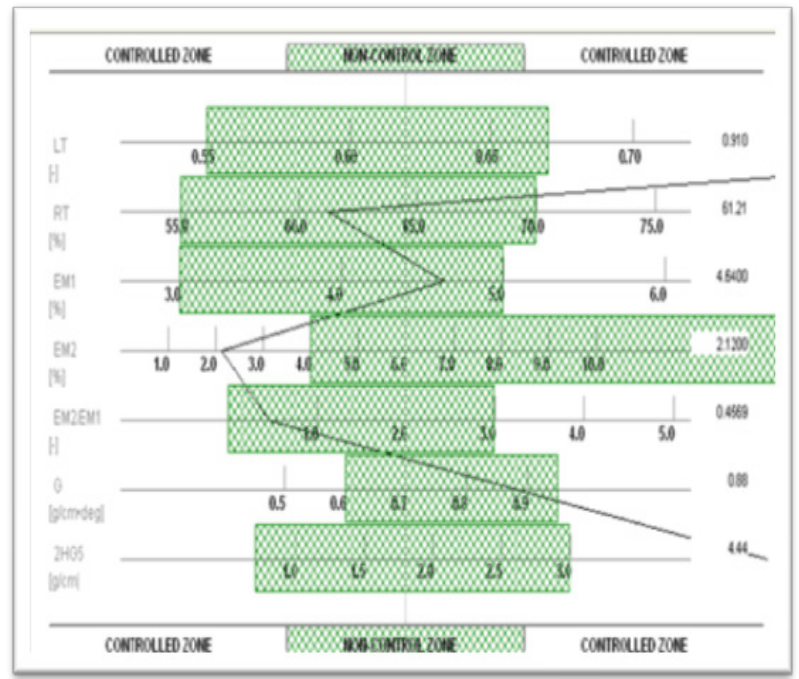

Figure 10 Tailor ability chart after plasma treatment.

\section{Conclusion}

The degumming process reduces the silk yarn strength to a certain extent. The plasma treatment on silk yarn creates surface roughness and also reduces the silk yarn strength to certain extent. The plasma treatment on silk yarn enables the silver wire gets wrapped on firmly to the silk core. The change in duration of plasma treatment is indirectly proportional to the yarn tenacity. The increase in plasma treatment duration reduces the yarn strength drastically. The increase in gold coating $\%$ of zari also reduces the strength yarn, since the zari yarn becomes stiffer due increase in coating\%. The low stress mechanical properties measured using Kawabata evaluation system confirms that the zari yarn woven fabrics' comfort property is improved after plasma treatment when compared with the untreated fabric.

\section{Acknowledgments}

None.

\section{Conflict of interest}

Author declares there is no conflict of interest in publishing the article.

\section{References}

1. Charles Tomasino, Cuomo JJ, Smith CB.Plasma Treatments of Textiles. Journal of Coated Fabrics. 1995;25:115-127.

2. Qufu Wei, Wang Y, Yang Q, et al. Functionalization of Textile Materials by Plasma Enhanced Modification. Journal of Industrial Textiles 2007;36(4):301-309

3. Sun D, Stylios GK. Investigating the Plasma Modification of Natural Fiber Fabrics-The Effect on Fabric Surface and Mechanical Properties. Textile Research Journal. 2005;75(9):639-644.

4. Rombaldoni F, Montarsolo A, Mazzuchetti G. KES-F Characterization and Hand Evaluation of Oxygen Plasma-Treated Wool Fabrics Dyed at Temperature Below the Boil. Textile Research Journal. 2010;80(14):1412-1421.

5. Bhat NV, Nadiger GS. Effect of Nitrogen Plasma on the Morphology \& Allied Textile Properties of Tasar Silk Fibers and Fabrics. Textile research journal. 1978;48(12):685-691.

6. Verschuren J, Kiekens P. Textile-specific Properties that Influence Plasma Treatment, Effect Creation and Effect Characterization. Textile Research Journal. 2007;77(10):727-733.

7. Karahan HA, Özdog an E, Asli Demir, et al. Effects of Atmospheric Pressure Plasma Treatments on Some Physical Properties of Wool Fibers. Textile Research Journal. 2010;79(14):1260-1265.

8. Hesse A, Thomas H, Höcker H. Zero AOX Shrink Proofing Treatment for Wool Top and Fabric: Part 1: Glow Discharge Treatment. Textile Research Journal. 1995;65(6):335-361.

9. Binias' D, Włochowicz A, Binias' W. Selected Properties of Wool Treated by Low-temperature Plasma. Fibres \& Textiles East Eur. 2004;12(2):58-62.

10. Kan CW, Chan K, Yuen CWM, et al. Surface properties of low temperature plasma treated wool fabrics. Journal of Materials Processing Technology. 1998;83(1-3):180-184.

11. Lam YL, Kan CW, Yuen CW, et al. Low stress mechanical properties of plasma-treated cotton fabric subjected to titanium dioxide coating. Textile Research Journal. 2011;81(10):1008-1013. 
12. Boonla K, Saikrasun S. Influence of silk surface modification via plasma treatments on adsorption kinetics of lac dyeing on silk. Textile Research Journal. 2013;83(3):288-297.

13. Ron Postle, Gu Ping. Objective evaluation of silk fabrics. Indian Journal of Fibre and Textile Research. 1994;19:156-162.
14. Sharma IC, Mukhopadhyay A, Sinha PK, et al. Comfort properties of mulberry and tasar silk fabrics. Indian journal of Fibre and Textile Research. 2000;25:52-58.

15. Radhalakshmi YC, Somashekar TH, Subramaiun V. Suitability of modified method for evaluating low-stress mechanical properties of silk fabrics. Indian Journal of Fibre and Textile Research. 2009;34:283-286. 